\title{
IDENTIFICADORES JUDÍOS Y SU MANIFESTACIÓN EN EL JUDAISMO LATINOAMERICANO
}

Jewish identifiers and their manifestation in Latin American Judaism

\author{
Deby Roítman ${ }^{1}$ \\ debyroít@holmaíl.com
}

\section{RESUMEN}

En este artículo se describen los conceptos de grupo étnico y de identidad. La identidad como unidad de distinción de un grupo determinado y sus identificadores como rasgos diferenciadores y aquellos que marcan las fronteras entre el "Ellos" y el "Nosotros". La identidad como construcción que contiene rasgos esenciales, los que vienen acompañados de elementos de cambio que van evolucionando y acoplándose con el paso del tiempo. Tomamos al colectivo judío dentro de la categoría de grupo étnico, por ser un grupo que ha logrado perdurar a lo largo de la historia de la humanidad. Se señalan cinco identificadores judíos generales: religión, tradiciones, conciencia de pueblo, Israel y Holocausto, para luego tomar estos elementos identitarios e indicar cómo estos rasgos se manifiestan y exhiben dentro del grupo judío latinoamericano en particular.

PALABRAS CLAVE: identidad, grupo étnico, judaísmo, Latinoamérica.

\begin{abstract}
ABSTR;ACT
In this article are described the concepts of ethnic group and identity. Identity as a distinctness unit of certain group and their identifiers as features wich delimit the frontlers between "Them" and "Us". Identity as a construction that contains essential features, where their contents evolves and adapts as times goes by. The Jewish collectivity is considered within the catcgory of ethnic group, because is a group that has achieved permanency in spite of the internal and external changes. Five general Jewish features are pointed out: rcligion, traditions, Jewish peoplehood, Israel and Holocaust. These identity elements are beíng briefly described as well as how they are manifested and exhibit within the Latin American Jewish group.
\end{abstract}

\footnotetext{
${ }^{1}$ Deborah Roitman es una habitual colaboradora del Centro de Estudios Judaicos en la dictación de sus diplomados.
} 
KEY WORDS: Idcntity, Ethnic group, Judaism, Jewishness, Latín America.

\section{INTRODUCCIÓN}

En la actualidad, gran parte de los procesos de globalización, a la vez que intentan la homologación y la uniformidad de estilos, conductas e ideologías en diversos ámbitos de la vida humana, también conllevan y revelan el efecto contrario: la persistencia de las particularidades, tanto en lo individual como en lo colectivo. Indudablemente esto último se vincula directamente con la identidad; poniendo de relieve el pluralismo y el reconocimiento de las distinciones dentro de un mundo cada

vez menos diferenciado.

El pueblo judío, a nivel colectivo e individual, a lo largo de su deambular diaspórico, permanentemente ha simbolizado la alteridad, lo raro, lo extraño, lo extranjero, lo innombrable, en fin, la representación del "Otro" frente al "Nosotros". Tanto si es voluntariamente asumida por los judíos o impuesta por un contexto externo (comúnmente hostil y antisemita), o ambas, la experiencia judía de ser diferente ha sido un componente central de la identidad judía.

En este artículo nos enfocaremos en la identidad como fenómeno de pertenencia y de diferenciación. Siendo el grupo judío el eje rector, este se contempla como un grupo étnico; comenzaremos indagando brevemente a qué nos referimos con la categoría de grupos étnicos, para llegar más adelante a definir qué es la identidad y sus identificadores. Proseguiremos señalando los identificadores judíos seguidos de una descripción de cómo estos rasgos se localizan y manifiestan dentro del judaísmo latinoamericano. 


\section{GRUPOS ÉTNICOS E IDENTIDAD COLECTIVA}

De acuerdo a Barth ${ }^{2}$ el grupo étnico es aquel que "en gran medida se perpetúa biológicamente; comparte valores culturales fundamentales realizados con unidad manifiesta en formas culturales; integra un campo de comunicación e interpretación; y cuenta con miembros que se identifican a sí mismos y son identificados por otros y que constituyen una categoría distinguible de otras categorías del mismo orden".

Continuando con esta línea se puede agregar que los grupos étnicos comparten intereses, instituciones y cultura: un interés compartido para la autopreservación; la cultura, como rasgo compartido por el grupo; y las instituciones que forman y conforman comunidad (de tipo religioso, social y de beneficencia, entre otras) y todos, en conjunto, se enfocan y abocan a su continuidad y preservación.

El grupo judío, a lo largo de toda su historia, ha mantenido ciertos valores, conductas, tradiciones y lenguajes comunes entre sus integrantes, que generalmente difieren de aquellos de la sociedad que los rodeaba, y ha prevalecido un fuerte deseo de mantener y continuar con sus características particulares. Estos atributos lo ubican en la categoría de grupo étnico.

Concibiendo a la identidad como la capacidad de diferenciarse y ser distinguido frente a los otros, implica el testimonio de las divergencias. Es justamente la identidad la que por un lado me diferencia del otro, a la vez que me une a mi grupo y permite, tanto al individuo como al grupo, querer pertenecer y formar parte de un colectivo particular. A nivel colectivo, las distinciones entre el "Ellos" y el "Nosotros" se manifiestan a través de los principios de diferenciación y de aleación. La diferenciación se refiere a lo que me hace diferente al otro, es la afirmación de la diferencia con respecto a otros individuos y otros grupos; es un vínculo con la esfera de lo externo a través de lo común-interno. La aleación o la integración unitaria significan la fusión y

2 Barth 1976: 11. 
los lazos comunes con el nosotros; son las características comunes que comparten los miembros del endogrupo. Por lo general resulta que los rasgos que marcan la diferencia con los "Otros" son los mismos que conforman y permiten la unión y aleación al "Nosotros",

La identidad se atribuye siempre en primera instancia a una unidad distinguible. En el caso de las personas y de los grupos, la distinción tiene que ser percibida y reconocida por los demás en contextos de interacción. Significa que también se tiene que tener la capacidad de reconocerse y de ser reconocido como portador de una

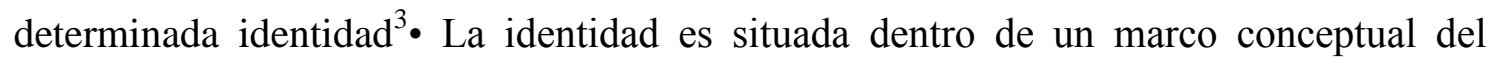
vínculo: la afinidad y afiliación que asocia a aquellos que se identifican, que extiende entre ellos un sentido común, o un espacio unificador, con base en la similaridad de sus integrantes. Es un lazo que une a los miembros del colectivo, la sensación de pertenencia frente a un grupo específico.

\section{IDENTIDAD- IDENTIFICACIÓN - IDENTIFICADORES}

Si la identidad es el significado para un individuo de pertenecer a un grupo, entonces toda identidad se relaciona con el significado de "singularizar": distinguir algo como una unidad en el tiempo y el espacio, discernible de los demás.

La identificación se refiere a los actos y procesos de afiliación a un grupo constituido por las notas que lo singularizan frente a los otros y a los demás y permanecen en él mientras sea el mismo objeto. Es la percepción del individuo de los atributos del grupo de referencia, su sentimiento frente al mismo y la extensión en que las normas de este son adoptadas por él mismo como fuente de referencia.

Bajo los supuestos anteriores, identificar a un pueblo sería señalar ciertas notas

\footnotetext{
${ }^{3}$ Giménez 1997 Y 1994
} 
duraderas que permitan reconocerlo frente a los demás, tales como territorio que habita, composición demográfica, lengua, instituciones sociales, rasgos culturales. Establecer su unidad a través del tiempo remitiría a su memoria histórica y a la persistencia de sus mitos fundadores ${ }^{43}$.

La esencia de la identidad es su "distinguibilidad"; esta supone la presencia de elementos, marcas, características o rasgos distintivos que definan de algún modo la especificidad, la unicidad o la no sustituibilidad de la unidad considerada ${ }^{5}$ Esto significa la percepción de una unidad que establece los límites o fronteras del espacio identitario, lo que permite distinguirlos de los demás. Entonces, para determinar quién pertenece al grupo y quién no, los grupos definen fronteras. Estos límites están marcados siempre por marcas o factores de naturaleza simbólica o cultural.

Los límites pueden ser manifestados de diversas formas ${ }^{6}$ Cuando un grupo étnico cierra sus puertas al mundo exterior y no permite la entrada de externos, logra el aislamiento de sus miembros de influencias exógenas y preserva su cultura única. Otra frontera paralela sería el aislamiento social; cuando un grupo habita un ambiente urbano de tipo plural mantiene fuera a una comunidad particular que está saturada con los artefactos de su cultura y religión. El lenguaje también es un tipo de frontera. Cuando los miembros del grupo hablan en público su lenguaje originario, se mantiene la cohesión del grupo frente al otro, a lo externo.

La identidad, como función diferenciadora, permite tanto al individuo como al grupo encontrar y ubicar su posición dentro de un contexto determinado (o varios, si así fuera el caso); se ubican -y a su vez se marginan en relación con el Otro; se tejen fronteras y se excluyen. Las fronteras se prestan para diferenciar entre el "Nosotros" y el "Ellos", Cada grupo tiene sus propios rasgos que son particulares de sí mismo y son los que lo distinguen

4 Villoro 1998:63-64.

5 Giménez 1997:12.

6 Linzer 1996: [43-144. 
de los demás. A estas peculiaridades denominaremos identificadores. Estos identificadores son parte de una serie de dominios o esferas cognitivas que conforman la identidad colectiva. De este modo mantiene la viabilidad y distinción del grupo.

En muchos casos es la cultura la que contribuye a la demarcación de las fronteras del grupo, las cuales psicológicamente (y también en el mundo real) separa a aquellos que comparten determinadas características culturales de aquellos que son percibidos que no participan en ella. Los límites étnicos conducen a la creación y la transformación de la cultura y así se imbuye la diferenciación entre sus miembros con contenido, sentido y significado.

Identificar siempre un rasgo distintivo y diferenciador. La frontera entre los grupos así constituidos está marcada por una posesión o carencia del trazo identificatorio específico, el que, al no ser una esencia sino una construcción, hace que esta frontera sea móvil y cambiante. De modo que una vez más confirmamos que la noción de identidad sólo cobra sentido en el contexto de las diferencias.

En resumen, los atributos identificadores, a nivel individual se refieren a los rasgos de la personalidad corno el ser inteligente, perseverante, creativo; a nivel colectivo los atributos son aquellos rasgos que pertenecen particularmente a cierto grupo y los distingue de los demás, y a través de los cuales es posible ser identificados ${ }^{7}$ - Son, corno ya se mencionó con anterioridad, los identificadores.

\section{IDENTIDAD COMO PROCESO DE CONSTRUCCIÓN: CAMBIOS EN LA IDENTIDAD JUDÍA}

\footnotetext{
${ }^{7}$ Aquí entraría el problema del estereotipo o prejuicio y del estigma con respecto a determinada categorías o grupos, pero no vamos a entrar con detalle. Giménez 1997: 15.
} 
La identidad cuenta con la capacidad de perdurar (aunque sea imaginariamente) en el tiempo y en el espacio. Implica la percepción de ser idéntico a sí mismo a través del tiempo, del espacio y de la diversidad de las situaciones. La dialéctica entre permanencia y cambio; más allá de sus variaciones accidentales y de sus adaptaciones al entorno.

El concepto de identidad colectiva es considerado como un fenómeno de carácter dinámico, flexible, relacional y procesal; las identidades emergen y varían con el tiempo, son negociables, se retraen, expanden o resurgen según las circunstancias. Este dinamismo no descarta ni se opone a la existencia de un núcleo esencial dentro de la identidad misma, el cual puede perdurar con el tiempo, a la vez que experimenta todo tipo de alteraciones. La reconstrucción, reelaboración y reconstitución de las identidades implica procesos de adscripción y exclusión mediante los cuales los sujetos sociales crean, seleccionan, desechan o afirman marcas o rasgos de identificación que son reelaborados simbólicamente y que les permiten aglutinarse como unidad en tomo a un proyecto determinado. Se promueve en función de que un grupo social se considere con derechos para identificarse y actuar sobre un universo de elementos culturales que considere propios y que le permita caracterizarse como diferente a otros ${ }^{8} \bullet$

La identidad judía como identidad colectiva no ha sido ajena a los cambios. Ha evolucionado y se ha transformado a lo largo de su interacción con factores de tipo social, político, económico y geográfico, entre otros. No obstante, siempre ha procurado mantener algunos rasgos esenciales dentro de sí mismo. A pesar de que el pueblo hebreo tiene más de dos mil años de historia, son particularmente las trasformaciones que se presentan a partir de la Modernidad las que vienen a alterar el concepto de identidad judía que se tenía hasta ese momento.

Hasta finales de la Edad Media y anterior a los cambios producidos a partir de la Revolución Francesa ${ }^{9}$, al interior del grupo judío la religión era la marca dominante de la

\footnotetext{
${ }^{8}$ Bonfil 1991 :66, Pérez Ruiz, 1992.

${ }^{9}$ El tomar como punto de partida los procesos históricos a partir de la Modernidad, y particularmente en
} Cuadernos Judaicos ISSN: 0718-8749 Volumen Aniversario 50 años 
pertenencia colectiva y la identidad grupal. Con la irrupción de la Modernidad y la conformación de esferas sociales diferenciadas, la religión debió compartir con otros referentes y dimensiones su rol histórico. La identidad judía se comienza a disociar en ámbitos como lo religioso, lo étnico, lo cultural, lo político y lo nacional, anteriormente inseparables, y se desarrolla un proceso de flexibilización, diversificación y rearticulación religiosa que permite la redefinición del lugar de los rituales y las prácticas judías tradicionales ${ }^{10}$ - Las transformaciones que se dan en la Modernidad se expresan; a su vez, en nuevas formas de existencia y de identificación judía, así como en novedosas estructuras comunitarias y organizativas.

La entrada en la Modernidad significó, grosso modo, la ampliación de las alternativas de cómo ser judío ${ }^{11}$. El pluralismo, expuesto a través de las múltiples alternativas dentro del judaísmo, significó la posibilidad de convivencia de diferentes ejercicios de lo judío y autodefiniciones de lo que es ser judío.

Actualmente, los mapas de identidad judía están siendo re-trazados con el propósito de reflejar nuevas realidades de la religión, cultura, demografía y las definiciones de la diferencia en el ámbito judío. Estos planos reconocen la permeabilidad de las fronteras, así como los límites que forman la base para la percepción identitaria que es al mismo tiempo fluida y cambiante. El judío decide de forma individual lo que significa pertenecer al judaísmo, con quién afiliarse e inclusive elegir cuáles son las obligaciones que esta pertenencia [le] implica.

Comienza a sobresalir el pluralismo como base ante las variadas formas que surgieron en relación con cómo expresar y practicar el judaísmo. Gran parte de estos cambios se dieron con una férrea intencionalidad de seguir manteniendo la identidad judía aunque ya

Europa, no significa que anteriormente no se hayan dado transformaciones relevantes dentro del marco del judaísmo, pero para los fines de esta investigación se recurrió a este período por ser aquél que cambió, de forma radical, el perfil del judaísmo.

${ }^{10}$ Sacks 1994.

${ }^{11}$ Webber 1992, Elazar, 1999, Eísen, 1998; Bírnbaum \& Katzenelson, 1995; Encyclopaedia Judaica, 1999, Vol. 7, pp. 1433-1452; Katz 1998; Barón, 1965. 
bajo las nuevas condiciones de vida que acompañaron a la Modernidad. Es la permanencia en el cambio: seguir siendo judío ante la apertura social, política, económica y cultural del mundo que los rodea, bajo nuevas y diversas modalidades.

Actualmente, el judaísmo se afirma como un conjunto interactivo de múltiples componentes - religión, historia, pueblo, tradición, moral, ética, hábitos, sentimientos, actitudes, normas y valores-, que se organizan de manera diferente y dispareja. Herman ${ }^{12}$, estudioso del judaísmo en la Modernidad, definió al judaísmo como una "conjunción de componentes religiosos (tradicionales) y nacionales (pueblo) inexplicablemente unidos y tejidos entre sí", lo que arroja luz sobre un sustrato común, así como sobre su diversidad interna.

\section{IDENTIFICADORES JUDÍOS Y SU DESARROLLO}

Frente a los cambios, cabe preguntarse ¿cuáles son, en la actualidad, las variables reconocibles de la identidad judía? ¿Qué identifica a un judío como tal? ¿Cuáles son los elementos que lo caracterizan?, y por ende ¿qué lo representa como diferente?; en síntesis: ¿Cuáles son sus identificadores?

En la mayor parte de la bibliografía, aun bajo la bandera del pluralismo interno, los rasgos que caracterizan al pueblo judío siempre han estado patentemente definidos por sus integrantes.

Los identificadores no solo engloban toda una fuente de saber, conocimientos, prácticas y observancias milenarias sino que también se traslapan entre sí, conformando un entretejido de elementos no siempre factibles ni fáciles de separar.

A través de la literatura relacionada al tema de la identidad judía y sus procesos, aunado

\footnotetext{
${ }^{12}$ Herman 1977.
} 
a la revisión de varios cuestionarios enfocados al ámbito de lo judío, resaltaron cinco identificadores: religión, conciencia de pueblo, tradiciones, Holocausto e Israel.

En el terreno de los identificadores se debe señalar que no todos los judíos se vinculan y relacionan con igual intensidad, peso y valor con cada uno de estos rasgos. Para cada judío el valor de estos es diverso, lo cual denota la multiplicidad interna del grupo en cuestión, ya que cada individuo judío se apoya y favorece más a uno o a otro de estos elementos.

La idea es la de exponer los identificadores, cada uno de forma general, y después señalar cómo estos rasgos se manifiestan en el grupo judío latinoamericano en la actualidad .

\section{RELIGiÓN}

El judaísmo, como la primera religión monoteísta, basada en la creencia en un Dios omnisciente, omnipotente y providente y centrado en la Alianza o Pacto. Se manifiesta principalmente en un complejo de creencias, normas y valores particulares, aunado a la constante realización de prácticas tradicionales. Estos cumplimientos se basan en las enseñanzas contenidas en la Torá, el Pentateuco, compuesto por cinco libros. Estos a su vez, conforman uno de los tres libros del Tanaj, la Biblia. La tradición oral rige la interpretación del texto bíblico; la codificación y comentario de esta tradición ha dado origen a la Mishná, al Talmud y a un enorme cuerpo exegético, desarrollado hasta el día de hoy por los estudiosos. El compendio de estos textos forma la denominada Ley Judía o Halajá. Consecuentemente, las normas derivadas de tales textos y de la tradición oral constituyen la guía de vida de los judíos, aunque la observancia de las mismas varía mucho de unos grupos a otros.

El judaísmo, a raíz de la secularización en la edad moderna, otrora anclado en su concepción tradicionalista, gradualmente generó en su interior denominaciones religiosas cuyas diversificaciones surgen a partir de la selección y la resignificación de la observancia de los preceptos y rituales judíos. Son básicamente tres las denominaciones 
religiosas que dominan el espectro religioso.

La fragmentación en el campo religioso surge a raíz de la fundación del Movimiento Reformista judío a principios del siglo XIX en Alemania. Este movimiento trazó su espíritu de libre cuestionamiento a partir del proceso de aplicar al judaísmo ideas modernas de la cultura intelectual de la Europa de ese siglo; particularmente aquellas teorías relacionadas con el cambio y el progreso. En su momento pretendió reformar la religión para despojarla de su carácter étnico-grupal y conferírle una dimensión individual-privada, tanto en el ámbito normativo como en lo ritual. Se enfocó fundamentalmente como una religión, es decir, una comunidad de creyentes en un Dios único. Se comenzó con un nuevo estilo de sinagoga, denominado templo, que justificaba sus innovaciones con bases tradicionales, aunque también tomaron el modelo de los servicios de la iglesia para sus rezos vernáculos, los sermones, el coro, el órgano y el sentarse hombres y mujeres juntos. Un número de doctrinas fueron consideradas anticuadas, entre ellas la expulsión de todo lo referente al Mesías, la tierra de Israel y Jerusalén dentro de los rezos, con significados meramente simbólicos ${ }^{13}$. A esto se les suman algunas permisiones a mujeres para fungir como rabinos, función tradicionalmente reservada solo para varones. Este movimiento ha sobrepasado los límites halájicos de las definiciones sobre quién es judío al incluir la descendencia patrilineal; acción que permite mayor aceptación de los matrimonios exogámicos, particularmente a sus hijos, bajo el lema de afiliar en lugar de alejar.

El Movimiento Conservador es aquel que aboga para que el judaísmo tradicional se adapte al ethos moderno. Este movimiento emergió a finales del siglo XIX de la Alta Escuela en Alemania, la cual adoptaba la occidentalización de las costumbres del judaísmo aunque fuera de corte más tradicional que el Movimiento Reformista. El primer seminario teológico rabínico se fundó en Nueva York en 1887 para capacitar a rabinos tradicionales. El carácter de este movimiento fue moldeado por Solomon Shechter, quien fue a esta ciudad desde Cambridge, Inglaterra, a dirigir dicho seminario en 1902. Actualmente, el Movimiento Conservador es la institución judía de mayor magnitud en los Estados Unidos

\footnotetext{
${ }^{13}$ Webber 1992
} 
y Canadá.

El Movimiento Ortodoxo abarca a quienes interpretan su judaísmo a través de la observancia de los preceptos, los principios de la fe y de las reglas de la Halajá, la Ley Judía. Este movimiento comenzó englobando a los judíos tradicionalistas que negaban las reformas religiosas del siglo XVIII. Actualmente este término es aplicado a quienes interpretan su judaísmo a través de la observancia de los preceptos, los principios de la fe y seguimiento de las reglas de la Ha/ajá.

Frente a la creación de esta categorización en el área religiosa, Sacks ${ }^{14}$ argumenta que el judaísmo pasa de ser sustantivo a ser adjetivo; lo cual significa que a partir de esta clasificación a los judíos se les tiene que nombrar para ser diferenciados entre ellos mismos. Tipificación que no existía previa a la Modernidad, debido a que no era necesaria: la mayoría pertenecían a la categoría que hoy denominamos ortodoxa. A partir de esta nueva diferenciación aumenta la pluralidad y provoca una heterogeneidad de tipo religioso antes desconocida dentro del judaísmo.

Un fenómeno de orden universal que se debe de recalcar en la actualidad y que también es inclusivo del judaísmo, es la "vuelta a las raíces religiosas", fenómeno que en el judaísmo se denomina la teshuvá. Esta nueva situación, la cual va en aumento y recluta a muchos individuos judíos no religiosos, implica el comenzar con la observancia de las prácticas del judaísmo bajo la adopción de un estilo de vida de carácter ortodoxo. Este proceso sucede más comúnmente dentro de la población judía juvenil que, en varias ocasiones busca su integración a un mundo más ordenado y seguro y cómo una reacción ante las múltiples posibilidades de opción que ofrece el mundo "de afuera". Son individuos judíos que persiguen nuevos y diferentes referentes identitarios que en muchas ocasiones los encuentra precisamente dentro de su propio grupo, aunque de forma extremista.

\footnotetext{
${ }^{14}$ Sacks 1994:26-27
} 


\section{TRADICIONES}

Una de las zonas de flexibilidad de mayor proporción que se presentó dentro del judaísmo es aquella que señala el cambio de preceptos a tradiciones. Dios, fe, creencia o revelación son relegados a un segundo plano en lo relativo a la práctica de los preceptos religiosos y colectivos, siendo reemplazado por las tradiciones.

A partir de la Modernidad, en varios sectores del judaísmo se deja de fundamentar y justificar las prácticas en valores religiosos y se sustituyen con valores e interpretaciones seculares. La autoridad de las prácticas religiosas fundadas hasta ese momento en la indudable creencia en Dios, entra en discusión, en duda y en disenso y la observancia de los preceptos pasan a ser actos independientes a esta creencia. Así, cuando a los mandatos se les suprime su significado religioso y de fe, resultan en tradiciones, su paralelo de corte secular.

La tradición, entendida como una serie de presunciones transmitidas de una generación a otra por medio de las cuales la gente procura sentido a su mundo y establece un sentido de identidad, continúa siendo clave y se ajusta a los nuevos tiempos.

Las tradiciones judías observadas en la actualidad son aquellas que ayudan a mantener parte de las "mínimas" distinciones frente a los gentiles y convierte a los rituales en actos meramente simbólicos, una práctica usual, que no siempre tiene que ver con la creencia y la fe en $\operatorname{Dios}^{15}$. De todas formas, lo relevante que la tradición trae consigo es la manifestación de la relación con el pasado como pertenencia, su transmisión y su continuidad.

Los significados e interpretaciones dados a las prácticas distintivamente judías ya han perdido su interés en los detalles de la observancia, así como, en ciertas ocasiones, es

\footnotetext{
${ }^{15}$ Eisen 1998.
} 
indiferente su contenido. En su lugar, el valor está colocado y centrado en la emoción y los sentimientos (a veces inclusive creados) más que en lo cognitivo. Es aquí donde, de acuerdo a Eisen ${ }^{16}$, aparece la función de la "nostalgia" como la razón más común para la observancia de las tradiciones en la actualidad, ya que es efectiva tanto a nivel cognitiva en lugares donde se enfatizan los caminos ancestrales más que en las formas específicas en que se debe de realizar, dejando únicamente su significado de tipo simbólico.

Los preceptos como tales no han dejado de ser importantes para el grupo judío, solo que a raíz de la pluralidad en lo referente a las definiciones del ser judío no tienen el mismo significado ni la misma simbología para todos por igual. No solo cambió su percepción e interpretación sino también en las prácticas estos comandos se flexibilizaron para lograr ser más acordes a la vida moderna con el propósito de continuar siendo judíos sin por ello dejar de integrarse al mundo circundante: no en oposición sino en paralelo. Así como la prioridad en las prácticas judías ha cambiado, también las retenciones, es decir, los rasgos presentes en una cultura o subcultura que son históricamente fáciles de seguir y de continuar en el periodo subsiguiente, pero los cuales pueden ya tener una nueva función. Los significados disponibles para las prácticas seleccionadas se han multiplicado y la aceptación de la observancia que no viene acompañada por la creencia, se ha extendido ${ }^{17}$. El judaísmo pasa a ser una persuasión religiosa la que puede ser aceptada o rechazada en donde se adoptan y se deciden aquellos aspectos del judaísmo que se quieren mantener, conservar, reformar y reconstruir ${ }^{18}$

Hoy en día es cada vez más difícil llegar a un consenso colectivo sobre los límites grupales y sus metas, ya que los acuerdos comunes son reemplazados por una multiplicidad de interpretaciones individuales. Adicionalmente ciertos rituales, tradiciones y ceremonias pasan a ser difícil es de proseguir y justificar, y esto hace que caigan en descrédito y sean puestos en duda. Rituales y ceremonias consideradas tradicionalmente menores han pasado

\footnotetext{
${ }^{16}$ Idem 1998.
} 
a tener mayor relevancia y observancia que otrora. Por ejemplo Januka, la fiesta de las luminarias, una fiesta menor en términos religiosos, ha pasado a ser una práctica visiblemente judía (particularmente en los Estados Unidos), patentemente debido a su paralelo con la Navidad y su concordancia con el sionismo y las ideas americanas de libertad religiosa. La ceremonia del Bar Mitzva, la cual se desarrolló a finales de la Edad Media, es actualmente un rito de iniciación crucial, entre la infancia y la adolescencia, donde el varón de 13 años (o la mujer de 12 años) pasa a ser considerado sujeto responsable dentro de la comunidad. Rosh Hashaná, Yom Kipur y Pesa\} continúan siendo ceremonias centrales. Otros rituales y observancias han declinado en importancia y son generalmente poco observadas por judíos no ortodoxos, tales como Sucot y Shavuot. Todo esto tiene referencia con las zonas de flexibilidad y sus limitaciones.

Dentro del marco tradicionalista es muy posible que la vinculación grupal e individual con el judaísmo se articule en gran medida a través del sentido de etnicidad y comunidad, siempre son el patente propósito de continuidad. Consiste comúnmente en el mantenimiento de redes de asociación estricta o predominantemente judías, que incluyen contenidos culturales que no siempre están atadas al aspecto religioso, no obstante éstos se mantengan presentes y entremezclados. A su vez, viene acompañado de un compromiso con el colectivo judío: solidaridad y empatía entre y por sus miembros.

En esta estructura, la religiosidad pierde la exclusividad y está más bien traslapada con lo cultural $^{19}$ • Así, para quienes se consideran tradicionalistas, el judaísmo se aprecia como un recurso más bien de tipo cultural, en torno al cual desarrollar aspectos existenciales de su vida personal, familiar y social ${ }^{20}$.

\section{CONCIENCIA DE PUEBLO - PEOPLEHOOD}

19 DellaPergola 2001 a.

20 Hamui 2003. 
El judaísmo, desde sus inicios, ha estado acompañado del "vínculo étnico" que de forma significativa conjuga tanto a los ancestros como a las prácticas culturales y que ha sido factor y recurso que ha conservado la unidad del pueblo a lo largo de su dispersión. La conciencia de pueblo se halla en clara relación con la etnicidad, refiriéndose a la combinación de parentesco y de costumbres, ambas reflejando genealogía compartida y comportamiento común. Paradójicamente, para los judíos la otredad frente a lo endógeno le da una sensación de unidad, a pesar de la diversidad etnográfica y territorial del pueblo judío; el colectivo tiene conocimiento y está consciente de su sentido de formar parte de una "aldea global" judía.

La nueva realidad social de la Modernidad presentó la total reformulación de la naturaleza y el alcance de la identidad judía, admitiendo nuevas definiciones de membresía dentro del colectivo. Todo esto fue y trajo como producto en ciertos ámbitos del judaísmo la negación del liderazgo de la religión judía tradicional como aquella proveedora de los criterios legítimos de la identidad judía, y su reemplazo vino a ser el énfasis en la etnicidad judía - Jewish peoplehood ${ }^{21}$ •

Retomamos el concepto de etnicidad como la conciencia de un grupo colectivo que imparte un sentido de pertenencia derivado de la membresía a lazos comunitarios presuntamente relacionados (emparentados) por sus descendientes y su cultura común ${ }^{22}$. Estas características las vemos reflejadas en el colectivo judío: los judíos se perciben a sí mismos como pertenecientes a un mismo pueblo, reconociendo una esencia común que los define de forma distintiva frente a la sociedad mayoritaria de la que son parte. Este sentimiento de unidad y unicidad grupal coexiste junto a un manifiesto pluralismo interno. Aunque se tengan diferentes concepciones de lo que es el judaísmo, la mayoría de sus miembros, sea cual fuere su propia interpretación, concibe su identidad judía -y a la comunidad- como un referente relevante en el entendimiento de su ser y de su lugar en la

21 Webber 199

${ }^{22}$ Premdas 1997. 
sociedad $^{23}$

La palabra clave sería la pertenencia: tener un vínculo con algo y/o formar parte integral del mismo. Como bien lo dice Isaías Berlín"24: "Así como la gente necesita comer y beber, tener seguridad y libertad de movimiento, también necesitan pertenecer a un grupo. Despojados de esto, ellos se sienten aislados, solitarios, disminuidos, infelices. Ser humano significa ser capaz de sentirse en casa en algún lugar, junto con tu propia especie".

$\operatorname{Herman}^{25}$, en la década de los setenta reconoce a la interdependencia ${ }^{26}$ como la base de la pertenencia, donde inclusive los judíos que se ven disímiles a otros judíos se consideran a sí mismos como relacionados y vinculados a este grupo. Según este autor, la sensación de interdependencia y de una fe común representa la mínima base, el denominador común de la pertenencia judía en nuestros tiempos; y que, a pesar del crecimiento de la diversificación de la vida judía, un núcleo de similaridad -origen común, tradiciones religiosas comunes- siempre se mantiene.

\section{ISRAEL}

El identificador Israel contiene toda una filosofía y un simbolismo que han acompañado al Pueblo Judío a través de su historia. El sentimiento frente a Sión proviene de antaño; procede de la eterna visión de Canaanan como la tierra prometida por Dios, con Jerusalén como su eterna capital; territorio del que fueron expulsados y exiliados y siempre, donde fuera que estuvieren, la añoranza por el regreso ha estado viva y presente. Desde la destrucción del Primer Templo, en el 586 a.e. y el exilio de Babilonia, los judíos anhelaban

\footnotetext{
${ }^{23}$ Buckser 2000:713 y 719

${ }^{24}$ Gardels 1991.

25 Herman 1977:43-44

${ }^{26}$ Interdependencia utilizado en el sentido de cuando un cambio de estado de una parte, afecta a la otra, lo que transportado al contexto de la vida judía significa que lo que sea que les pase a los judíos en donde fuere'
} 
el regreso a Sión. Este anhelo se expresaba a través de las plegarias y a través de varios momentos mesiánicos ${ }^{27}$.

Durante los siglos de exilio y diáspora, el lazo con la Tierra de Israel se mantuvo presente en el sistema de valores del Pueblo Judío y en su autoconciencia de grupo. Si este lazo se hubiera roto, el judaísmo se hubiera convertido en una mera comunidad religiosa, perdiendo sus elementos étnicos y nacionales con el vínculo existente, siendo que el grupo judío era considerado una minoría exiliada ${ }^{28}$. Todo esto se localizaba bajo un marco de fe y religión.

En contraste, el sionismo, movimiento de liberación nacional judío, iniciado en Europa a finales del siglo XIX, es un movimiento de carácter secular que buscó dar una respuesta acorde a los paradigmas conceptuales e ideológicos de la Modernidad que tiene sus raíces en el fracaso de la asimilación aunado a la decepción frente a la imposibilidad de una total emancipación en la Europa de Occidente, así como la intensificación del antisemitismo y el apogeo del nacionalismo en Europa ${ }^{29}$. Este movimiento constituyó la revolución más fundamental en la vida judía: sustituyó la auto identidad tradicional, la ortodoxa, basada en la religión, por una autoidentidad secular de los judíos como nación. Cambió la esperanza pasiva, quietista y piadosa del Retorno a Sión por una fuerza social efectiva que movilizó a millones de personas a Israel.

Este movimiento ofrecía a todos los judíos, sin importar cual fuese su percepción y entendimiento del judaísmo a nivel religioso, cultural o político, una oportunidad de

\footnotetext{
${ }^{27}$ Shlaim, 2001.

${ }^{28}$ Avineri,1993:13.

${ }^{29}$ Dado que el nacionalismo se desplegó fundamentalmente en terreno europeo y no tuvo presencia en el mundo árabe hasta el siglo XX, el sionismo es considerado esencialmente un movimiento europeo. Hasta la creación del Estado de Israel, la mayor parte de los pioneros que emigraron a la Tierra de Sión eran de origen europeo.
} 
identificarse activamente como $\operatorname{tal}^{30}$. A su vez, tuvo varias ramificaciones e interpretaciones, cada una influida por las ideologías de mayor fuerza en esa época: sionismo político, religioso, socialista, autónomo y otros. El sionismo elevó el carácter nacional de la herencia judía, su conexión con la tierra de Israel y la necesidad judía de un hogar nacional donde el propósito no era únicamente la creación de un Estado judío, sino la fundación de una nueva sociedad, basada en valores universales de libertad, democracia y justicia social ${ }^{31}$,

La ideología sionista enfatiza la visión del judaísmo como Pueblo (Am Israel). Afirma la naturaleza étnica del judaísmo que, al proyectarle un contenido político, intentó transformar al grupo étnico en una nación: "un grupo étnico con una bandera" ${ }^{32}$,,

El sionismo transformó el idioma hebreo, relegado al uso ritual, a la forma de comunicación secular de un Estado-nación ${ }^{33}$. Este movimiento trae la renovación de la existencia política judía dentro de un Estado independiente, Estas ideas, llevadas a la práctica, conducen al establecimiento del Estado de Israel en 1948 representando un logro esencial para el mundo judío siendo su instauración un acontecimiento sin precedentes en la historia judía desde sus inicios, Significaba reafirmar su derecho a ser una nación, a tener su propia tierra soberana para y por ellos mismos. Con esto culmina el milenaria deambular de los judíos. Se da un encuentro con la materialidad terrestre, perdida hace dos mil años ${ }^{34}$,

A partir de su creación, el Estado de Israel ha sido fuente primordial de identidad, tanto para aquellos que lo habitan como para quienes viven en la diáspora. Desde la Guerra de los Seis Días, en 1967, Israel se adviene como punto focal y medular en la identidad judía de la diáspora, aceptado virtualmente por el colectivo judío mundial, donde el rol crucial de Israel pasa a ser el de generar lazos judíos, más allá de las diferencias existentes en el

\footnotetext{
${ }^{30}$ E1azar 1999:38.

${ }^{31}$ Shlaím 2001

${ }^{32}$ Gitelman 1998:

${ }^{33}$ Avineri 1983:24.

${ }^{34}$ Rozitchner 2002:32
} 
interior del mismo ${ }^{35}$

No obstante lo anterior, en las últimas décadas del siglo $\mathrm{XX}$, el sionismo ha experimentado una profunda reinterpretación. En la actualidad existe un debate en cuanto al rumbo de este concepto y su ideología. Ya la centralidad del Israel y la alía (ir a vivir a Israel) no son condiciones necesarias para definir al sionismo ni al sionista. En palabras de Yehuda Bauer ${ }^{36}$ :

"... El sionismo de hoy en día es una ideología nacional judía que tiene dos aspectos: la identificación con Israel como centro político y tal vez cultural del pueblo judío (y no la identificación con un gobierno determinado ni con sus lineamientos políticos); y el reconocimiento pleno de la continuación de la universalidad del pueblo judío, y de la firme voluntad de salvar primero y desarrollar después en la diáspora, para que también allí florezcan centros culturales y espirituales que influyan sobre el Estado de Israel y se vean influidos por él sobre una base de reciprocidad e igualdad. La centralidad de Israel es una aspiración no una condición, y no implica control espiritual o cultural sino actuar a partir de una realidad en la que la sociedad judía soberana en la tierra de sus antepasados puede, al menos en principio, ofrecer contenidos que en otros lugares no puede desarrollar".

A partir de creación del Estado de Israel, la población judía mundial ha sido testigo de dos categorías de determinantes demográficos, de cierta forma conflictivas, bastante contrastantes y ampliamente diferentes entre sí $^{37}$ : la división bipolar que coloca a los judíos del Estado de Israel, como una minoría a nivel mundial que vive como mayoría en un Estado soberano ${ }^{38}$ por un lado; y los judíos de la diáspora, un conglomerado de judíos que conforman comunidades [etnias minoritarias] no soberanas delimitadas por las leyes del

\footnotetext{
${ }^{35}$ Bokser 2000; Encyclopaedia Judaica, 1999, Vol. 5, p. 851-53.

${ }^{36}$ Bauer 1997:88.

${ }^{37}$ Della Pergola 1998.

${ }^{38}$ La primera es una clase unitaria, la comunidad de Israel, donde los ciudadanos israelíes son gobernados por una autoridad que es judía, casi en el mismo sentido que decir que cl gobierno de Francia es francés. Es decir, los judíos son gobernados por judíos, por su propio pueblo. Esto existe con todas los aspectos de un gobierno soberano formal: policía, fuerzas armadas, adquisición tributaria, representación diplomática y el resto.
} 
país en que residen. Este corte produjo y marcó en gran medida la relación Israel-diáspora, también conocida como Centro-Periferia, respectivamente, que subsiste condicionada por los cambios y las evoluciones que se han suscitado a nivel local, regional y global; ya sea por razones internas del grupo judío como factores externos, de la sociedad mundial. El Centro es una noción de centralidad espiritual para la Periferia. La Periferia, cuyos problemas varían de lugar en lugar, ha desarrollado una lealtad múltiple: existe una relación entre Israel y la diáspora a través de apoyo formal y solidario; aunque se han ido acentuando las diferencias entre los judíos israelíes y los judíos de la diáspora tanto en lo referente al nivel de vida, como en lo cultural, lo político y lo religioso. Hoy en día, ya no existe una simetría de poder, como se hablaba en la década de los setenta al mencionar el "Poder compartido", ya que son dos mundos diferentes con Israel como el polo cuyas líneas de fuerza son cruciales en la habilidad de los judíos de orientarse a sí mismos ${ }^{39}$ •

Actualmente, cada comunidad de la diáspora se desenvuelve y se desarrolla a partir de sus propios procesos, de acuerdo a variables contextuales nacionales, regionales y globales, incluyendo al Estado de Israel, considerando que este último no siempre ocupa una posición esencial.

\section{HOLOCAUSTO}

El Holocausto o Shoá, término adoptado del hebreo para denominar la muerte de seis millones de judíos en manos de los nazis durante la II Guerra Mundial, ha sido una de las grandes tragedias del siglo XX, por muchos considerada la catástrofe judía sin precedentes ni comparación alguna. Significó la aniquilación sistemática y masiva de millones de individuos; donde perecieron dos tercios de la población judía y junto con ella el judaísmo europeo y sus grandes comunidades fueron borradas de la faz de la tierra ${ }^{40} \bullet$

\footnotetext{
${ }^{39}$ A su vez, se podría hablar de otra relación centro periferia, pero está dentro del marco de la judería de la diáspora, es decir, de la periferia misma. Es Estados Unidos el centro de poder de la diáspora judía mientras que todas las demás comunidades conforman la periferia.

${ }^{40}$ El Holocausto cambió el perfil del Pueblo Judío. En la segunda Guerra Mundial perecieron dos tercios de la Cuadernos Judaicos ISSN: 0718-8749 Volumen Aniversario 50 años 
Este acontecimiento se conmemora en el mundo judío el 27 de Nissan (según el calendario hebreo) que coincide con el día que se inició el levantamiento del gueto de Varsovia. En Israel se establecieron una gran cantidad de instituciones para la rememoración, fundamentalmente a través de trabajo educativo y de esclarecimiento. Estas son Yad Vashem, organización estatal en Jerusalén; Bel Lojamei Haguetaot, al norte de Israel; Moreshet, en el kibutz Yad Mordejai, al sur del país; y Masúa, en el centro de Israel. A su vez, también en ciudades de los Estados Unidos como Los Ángeles, Nueva York y Washington y en países como Polonia, Francia y Australia.

Bajo este rubro, es de suma importancia su relación con la memoria. La memoria, ya sea individual o colectiva, significa la presencia activa del pasado en el presente en función de un futuro deseado o de un horizonte de expectativas proyectado ${ }^{41}$ Para el pueblo judío, la valoración de la memoria histórica es una piedra angular de su tradición cultural y religiosa. La memoria del Holocausto se entrelaza con la necesidad de testimoniar y relatar; aquella que se centra en la comunidad de las víctimas, que sería la memoria colectiva tradicional (grupal, étnica, religiosa), en este caso, la memoria judía de la catástrofe ${ }^{42}$ De acuerdo con las características de la memoria judía del Holocausto y de sus formas de transmisión, esta memoria se trata de una concepción del testigo que se inscribe en la tradición judía del relato y la escucha: no importan tanto los hechos y los datos específicos de los acontecimientos como la conjura del olvido de la constante relectura y actualización de la memoria ${ }^{43}$ En el caso de la Shoá, lo relevante es no olvidar, ya que a raíz de "La Solución final" llevada a cabo por los nazis durante los últimos años de la segunda Guerra Mundial, un tercio de pueblo judío fue exterminado.

\footnotetext{
población judía; el judaísmo europeo y sus grandes comunidades fueron borrados de la faz de la tierra (Para mayores detalles sobre la demografía del pueblo judío anterior y posterior al Holocausto y su posible especulación ver artículo de S. Delia Pergola "Between Science and Fictíon (1996)). Para principios del siglo XX, el $81 \%$ de todos los judíos del mundo vivía en Europa (8,900,000 millones); actualmente solo un $15 \%$ de ellos vive en ese continente (Gutman \& Schatzker 1984; Gutman 2003).

${ }^{41}$ Bárcena 2004.

${ }^{42}$ Baer 2004:78.

${ }^{43}$ Idem 2004:92
}

Cuadernos Judaicos ISSN: 0718-8749

Volumen Aniversario 50 años 
Para poder comprender la complejidad de la memoria del Holocausto, se debe de entender el proceso de evocación de este mismo evento. En el periodo de posguerra, bajo el sistema de la Guerra Fría predominante en el mundo, se manifiesta la invisibilidad del Holocausto $^{44}$; acontecimiento que estaba subsumido a categorías como crímenes contra la humanidad, crímenes de guerra, a pesar de que existían pruebas, estudios y conciencia de su existencia ${ }^{45}$.

En Israel, el silencio sobre el Holocausto en parte se atribuye a la imposibilidad de integrar la tragedia en la narrativa nacional imperante, lo que domina es una escasa atención oficial al Holocausto. Losaños posteriores al Holocausto, el recuerdo del mismo es poco específico; y no existió como memoria colectiva más allá del propio colectivo de las víctimas judías, tanto en Israel como en otras partes del mundo ${ }^{46}$ •

En la década de los sesenta comienza un cambio en la conciencia pública sobre el genocidio judío: esta se singulariza. La memoria del Holocausto pasa de la esfera intracomunitaria al ámbito de lo público. Son varios los acontecimientos que sustraen al Holocausto de su estado de marginación a una esfera central. Se publica el Diario de Ana Frank en 1952; la película se proyectó en 1959. Se lleva a cabo el juicio de Adolf Eichman, en Jerusalén, en el año 1961. Fue por primera vez en este evento donde los términos Holocausto, y su análogo en hebreo Shoá (denominación dada por el escritor Elie Wiesel), pasan a ser empleados como sinónimos del genocidio ocurrido al pueblo judío en el periodo nazi $^{47}$.

El Holocausto se adviene como elemento de identidad en Israel y en la diáspora. Cabe destacar la relevancia de la participación de las elites judías norteamericanas, que a partir

\footnotetext{
${ }^{44}$ Idem 2004; Mintz, 2001

${ }^{45}$ Sánchez-Biosca 2004:1 16.

${ }^{46}$ Baer 2004; Mintz 2001.

${ }^{47}$ Baer 2004:82-84.
} 
de la Guerra de los Seis Días (1967), y más adelante con la Guerra de Yom Kipur(1973), ponen al Holocausto como valor central en la memoria del pueblo judío ${ }^{48}$. La Shoá se convierte en memoria colectiva de todo un pueblo y no solo de sus supervivientes.

Otros eventos también de suma importancia en el impacto de la Shoá a nivel público fueron la miniserie televisiva "Holocausto" en 1978 y, en otro nivel, la creación de una comisión gubernamental para la construcción de un museo memorial del Holocausto ${ }^{49}$ en Washington, ese mismo año.

En los setenta y ochenta, Israel deja de ser objeto romántico y heroico de identificación para los judíos americanos y mucha de esta energía, antes puesta en ayudar al Estado de Israel, pasa al tema del Holocausto, ya sea en preservar su memoria y/o en educar sobre él mismo $^{50}$.

Años después, en 1994, la película La lista de Schindler fungió como elemento educativo de alta relevancia en el mundo entero; al cual se le suma el proyecto de videograbación de testimo-nios Survivors olthe Shoá Visual History Foundation, ambas empresas realizadas por el director de cine judío estadounidense Steven Spielberg.

En parte debido a los eventos mencionados, el Holocausto no solo dejó la marginación de lado, sino que pasó de ser un fenómeno particular del pueblo judío, a un evento de carácter universal; es la interpretación judía de validez y usos universales ${ }^{51}$.

En la actualidad existe la "Marcha de la Vida", un programa de carácter global, que incluye tanto a individuos judíos de la diáspora como de Israel. Este plan implica un viaje al campo de exterminio de Auschwitz (conmemorando el día del Holocausto -Yom

\footnotetext{
${ }^{48}$ Sánchez-Biosca 2004: 116.

${ }^{49}$ La inauguración de este Museo en 1993, significó la hegemonización del Holocausto en Estados Unidos (Sánchez-Biosca 2004).

${ }^{50}$ Mintz 2001:164

${ }^{51}$ Mintz 2001; Baer 2004.
}

Cuadernos Judaicos ISSN: 0718-8749

Volumen Aniversario 50 años 
Hashoá) y otros campos de exterminio similares para finalizar dicho viaje en Israel (festejando el día de la independencia de Israel- Yom Haatzmaut). Asimismo existen otros viajes de estudios a varios campos de exterminios de Europa y visita a Polonia, esto último cómo intento de comprender cómo era la vida de las comunidades judías del este de Europa antes de la guerra.

El Holocausto, más allá de los escritos legados de los testimonios de las víctimas (Ana Frank, Elie Wiesel, Primo Levy, a modo de ejemplo), es un tema central de estudio en varias universidades. Su estudio es materia obligada en la red escolar del Estado de Israel, así como en muchas instituciones educativas de la diáspora.

El Holocausto prueba que el hombre moderno, a pesar del progreso en las esferas culturales, científicas y tecnológicas, no se ha vuelto más tolerante por el Otro, ni es sensible a su sufrimiento. Está claro que en tiempos de crisis, el hombre fácilmente adapta teorías e ideologías radicales y extremistas, y desarrolla un egoísmo de masas o colectivo. Es un fenómeno por el cual todavía el mundo (judío] continúa cuestionándose cómo sucedió.

\section{IDENTIDAD E IDENTIFICADORES EN EL JUDAÍSMO DE AMÉRICA LATINA}

A grandes rasgos, las colectividades judías de América Latina se perciben a nivel identitario y social como un grupo étnico. Un colectivo nutrido por la familia, el lenguaje y otros aspectos de la cultura y profuso apoyo al Estado de Israel, particularmente a través de la inmigración a Israel (aliá). La religión como un factor poco relevante dentro de este grupo regional.

Para recalcar lo anterior, tomando en consideración algunas tipologías sobre identificación judía en la población judía de Israel y en las comunidades más numerosas de 
la diáspora, Della Pergola ${ }^{52}$ observa que el principal elemento de identificación judía no es la religión, sino que está constituido por otros elementos o "modos". El modo de "etnicidad / comunidad" -mantenimiento de redes de asociación judías- tiende a ser el dominante en Israel, Canadá, Gran Bretaña, así como en los tres países latinoamericanos mencionados en el estudio: Argentina, Brasil y México ${ }^{53}$. Esta tipología de etnicidad-comunidad se puede hacer extensiva a todas las comunidades existentes en el continente latinoamericano.

Sería sumamente difícil poder describir al judaísmo latinoamericano especificando a cada uno de los identificadores descritos con anterioridad. En el caso de esta región, particularmente los elementos identitarios de religión, tradiciones y conciencia de pueblo se traslapan y coexisten de tal manera que no sería posible darles un "orden" particular y lineal. En estas comunidades se ha desarrollado y conviven juntos el ámbito religiosotradicional con las esferas educativas-culturales, las específicamente comunitariassectoriales, las de beneficencia y las de apoyo a otras comunidades judías en el mundo, así como las abocadas a la ideología sionista y a Israel. Es por esto que se irán describiendo y entrelazando los elementos identitarios que, en muchas ocasiones, son parte de uno o más de los identificadores judíos generales.

El judaísmo latinoamericano desde sus comienzos se componía de inmigrantes de diversos orígenes geográficos: sefardíes occidentales, de África del norte, judíos de Europa central y occidental, diversas regiones del decadente Imperio Otomano, de los Balcanes, Siria y Marruecos, judíos orientales de Oriente Medio, también denominados edot hamisraj $^{54}$. Esto provoca un gran mosaico, cuya heterogeneidad suscitó que la organización comunitaria se diera según sus países de origen. Esto es base para el principio de la

\footnotetext{
${ }^{52}$ Delia Pergola 1999,478-81.

${ }^{53}$ Caro 2008.
}

54

Avni 1992 Y 1999. 
identidad étnica a la que cada uno de sus integrantes pertenece. Cada uno de estos grupos traía con ellos rasgos particulares en tópicos tales como el idioma, liturgias o distintas costumbres culinarias. Así es como cada comunidad también se ocupa de otras áreas, como sería supervisión del kashrut, cortes rabínicas, cementerios y baños rituales.

Siguiendo esta pauta de sectorización comunitaria, la sinagoga es un elemento que manifiesta esta segregación. En sus comienzos la mayoría de las sinagogas fueron construidas bajo el manto de la ortodoxia, agrupadas alrededor de una comunidad de acuerdo con el lugar de origen; donde cada una cuenta con su propio rabino, su propio estilo de rezo y liturgia exclusiva.

No obstante, en la década de los sesenta llegó a establecerse el Movimiento Conservador a la Argentina, donde fue tomando fuerza. En la actualidad, es a través del Seminario Rabínico (ubicado en Buenos Aires), institución donde se capacitan e instruyen a rabinos, educadores y estudiosos identificados con este sector; y es desde aquí mismo de donde son enviados, ya con su especialización, a trabajar y asistir a las comunidades judías de Latinoamérica que lo requieran. En la actualidad, la mayoría de las colectividades del continente cuentan con rabinos conservadores, lo que indica un vuelco hacia ese tipo de denominación. Así es como muchas comunidades de la región han optado por el Movimiento Conservador como aquel que los rige en términos religiosos.

El Movimiento Reformista ha tenido pocos seguidores, y es en Brasil y poco menos en Argentina, donde parece ser más favorecida esta denominación.

Es relevante destacar que en las últimas décadas, la presencia de grupos ultra religiosos, particularmente el movimiento Jabad, es mucho más notoria y ha incorporado a sus filas particularmente a mucha juventud judía en búsqueda de identidad. El colectivo ultraortodoxo incorpora a judíos no religiosos a sus filas, adoptando la observancia de los preceptos como forma de vida habitual Este fenómeno, denominado teshuvá, se ha difundido por toda la región. Generalmente quienes más aceptan cambiar su estilo de vida "moderno" a uno ortodoxo, son los jóvenes. Muchas veces este es un grupo que busca seguridad y protección, las cuales encuentra dentro de su mismo grupo referencial (el 
judío), donde gran parte de sus opciones rutinarias sean menos amplias y difíciles, como lo son la "cultura de masas" universal, aunado a la búsqueda de certezas frente a un mundo de incertidumbres y todo converge en un solo camino: la vida cotidiana bajo el manto de la ortodoxia judía.

Muchos de los integrantes de las comunidades ya sea que estén afiliados a cualquiera de estas denominaciones, no necesariamente se identifican con las mismas por sus ideologías y pensamientos; más bien la razón de su membresía es la búsqueda de un sentido de comunidad, a través de un marco institucional de pertenencia. La mayoría de los judíos, en lo referente a su observancia religiosa se consideran "tradicionalista", vocablo o expresión que no pertenece a ninguna denominación, pero sin embargo refleja un carácter de facto del comportamiento derivado del reconocimiento del lugar que la religión y sus prácticas han tenido en la vida judía latinoamericana. Hamui ${ }^{55}$ describe al tradicionalismo judeo-mexicano, definición que bien puede ser aceptada y adoptada para describir a sus iguales judíos del sur del continente de la siguiente manera:

"El judaísmo para la mayoría, pasó de ser una religión a ser una tradición y la asociación voluntaria a la comunidad más un asunto social que espirituaL La pertenencia grupal se manifestaba en la participación en las instituciones judías: escuela, actividades sociales y culturales y en el mantenimiento de ciertas costumbres religiosas como la asistencia anual a la sinagoga en ocasión de las fiestas mayores y/o en la celebración religiosa de los momentos significativos del ciclo de vida judío como el Brith Milá (circuncisión), el Bat-Mitzva, el matrimonio judío o los ritos de defunción".

Esto nos lleva a reconocer y reforzar una de las características más notorias de este grupo: su carácter notablemente secular. La herencia laica, que venía acompañando a los inmigrantes europeos, se reveló contra sus acervos ultra-ortodoxos. Esta rebelión antirreligiosa tuvo eco y apoyo en América Latina, ya que al existir una religión mayoritaria (la católica), inclusive como religión "oficial", la conciencia de la sociedad mayoritaria no podía poner en igualdad de posición a las demás, aunque en el ámbito de

\footnotetext{
${ }^{55}$ Hamui 2003.
} 
derecho constitucional debería de ser reconocida como tal Así es como adherirse a la religión judía hacía al judío un poco menos igual ${ }^{56}$.

Fueron más bien los colegios judíos los que recuperaron este espacio capital, donde la "no centralidad de la sinagoga" se yuxtapone con la "centralidad de la escuela" ${ }^{57}$. Ciertamente, el surgimiento de la escuela "integral" como modelo dominante de instrucción judía fortaleció el sistema educativo judío [así como la identidad judía] de América Latina ${ }^{58}$. Otro factor que ocupó un espacio central fueron los clubes sociales, culturales y deportivos como espacio aglutinador.

Además de la escuela se puede agregar que la identidad judía se concentra alrededor de elementos nacionales, étnicos y culturales ${ }^{59}$. Estos tres elementos han sido hondamente manifestados bajo diferentes formas y espacios institucionales e ideológicos. En relación con lo étnico, cabe recordar el hecho de estar constituidos en comunidades de origen étnico que favorece la pertenencia al judaísmo como instancia de pueblo, lo que conlleva un alto sentimiento de conciencia de pueblo (Jewish Peoplehood); emoción reforzada por el carácter laico que enfatiza su identificación al judaísmo como pueblo y no como religión.

Este mismo elemento resalta la parte cultural del grupo; en este rubro todas las comunidades judías latinoamericanas desarrollaron vibrantes instituciones que han cubierto un amplio margen de asuntos y diversidad de proyectos. Gran parte de las instituciones judías que existen alrededor del mundo tienen su representación y su activismo también en

\footnotetext{
${ }^{56}$ Avni 1972:266.

${ }^{57}$ Levy 1987. El porcentaje de estudiantes judíos que concurren a escuelas judías es mucho mayor en América Latina que en la diáspora en general.

${ }^{58}$ Schmelz y DelIa Pergola 1985: 186.

${ }^{59}$ Uno de los acuerdos que predomina en gran parte de los debates acerca del sionismo en nuestros días es aquel que tiene que ver con la educación. Se denota un fuerte acuerdo de la relevancia del desarrollo y fomento de la enseñanza judaica -tanto en Israel como en la diáspora- con el propósito de un mayor acercamiento al judaísmo, independientemente del concepto de sionismo que se quiera utilizar o actualizar (Bauer, 1997).
} 
las comunidades judías latinoamericanas como son la Bnai Brith, el Karen Kayemet (Fondo Nacional Judío), el Karen Hayesod, la WIZO (Organización Internacional de Mujeres Sionistas), movimientos juveniles como Maccabi Hatzair, así como instituciones culturales que conjugan a Israel con el país local que habitan. Las actividades a las que se dedican las organizaciones varían; muchas están ligadas a Israel y al sionismo, a la vez que algunas se dedican a promover la tolerancia entre los pueblos, y otras promueven la beneficencia a nivel local. Algunos centros se enmarcan específicamente en el campo de los estudios informales, brindando la posibilidad a los integrantes de la comunidad que reciban educación en temas de interés judío, local y universal.

En la era de la tecnología, estas comunidades han sabido aprovechar sus ventajas: hoy todas las comunidades cuentan con su página en línea en Internet así como la mayoría de las instituciones ya mencionadas. En las comunidades de mayor tamaño cuentan con programas de radio, como es el caso de Radio Jai en Argentina, fundada en 1992. 
Tomando en consideración el asunto de la conexión entre judíos en un mundo tan extendido, existen páginas de Internet en español con posibilidad de conocer gente judía de la misma edad y con intereses similares.

Todo lo anterior habla de una dinámica y pujante organización comunitaria, que sin duda ha ido cambiado su imagen así como sus prioridades con la intención de adaptarse a los nuevos tiempos. Claro que a pesar de estas redes institucionales, de todas formas muchos judíos se alejan de los marcos comunitarios, en algunos casos continuando con su judaísmo de forma individual, otras veces, dejando el judaísmo desatendido sin darle un lugar prioritario en su vida.

A modo de resumen en lo referente a las tendencias en el ámbito identitario "comunitario" y "religioso" se podría citar a Caro ${ }^{60}$, quien argumenta que en la actualidad existen cuatro factores primordiales en lo relativo a la identidad y sus procesos, los cuales corren en paralelo y están interrelacionados ${ }^{61}$ : a) la constitución de identidades judías laicas, con elementos progresistas y liberales, sin que la religión sea necesariamente un elemento central de identificación; b) una tendencia a la consolidación de un espacio religioso ortodoxo, que puede alcanzar a un $10 \%$ de la población; c) la formación de nuevas identidades, muchas de ellas lejos de los marcos comunitarios institucionalizados; d) la consolidación de un debate que incluye tanto al judaísmo institucionalizado como al informal, que se plantea en tomo a una crítica al modelo comunitario centralizado" .

En lo relativo al elemento nacional, el sionismo y el Estado de Israel siempre han sido factores primordiales de la identidad judía. Importada la ideología sionista por los inmigrantes europeos, se transfirió y continúo desarrollándose en estas tierras. Muchas instituciones, tanto de tipo social como político o educativo, han tenido como base la ideología sionista y en algunos casos el hebreo como herramienta de identidad. Muchos judíos latinoamericanos son hebreo-parlantes gracias a su educación escolar hebraísta y sionista. Los movimientos

\footnotetext{
${ }^{60}$ Caro 2008

${ }^{61}$ Caro indica que esto sucede en el grupo judío de Argentina y Chile; no obstante esto puede ser extendido a las demás colectividades judías de la región en cuestión, que pasan por procesos similares en el rubro idcntitario
}

Cuadernos Judaicos ISSN: 0718-8749 Volumen Aniversario 50 años 
juveniles sionistas han tenido una fuerza relativa y han influido mucho en la educación informal e identidad sionista de las comunidades judías latinoamericanas. A su vez existen en casi todos los países instituciones de corte sionista como es la Agencia Judía y la Federación Sionista.

Esto no solo influye en la identidad judía local sino que ha sido fuente de empuje emigratorio. La población judía latinoamericana se ha caracterizado por su alta migración externa (outmigration). Siendo el sionismo una ideología predominante en la mayoría del continente en cuestión, ante la creación del Estado de Israel proporcionalmente muchos más judíos emigraron de Latinoamérica, que de cualquier otra región de la diáspora ${ }^{62}$. Los países de la región latinoamericana se han caracterizado por una situación inestable (crisis económicas, fuertes dictaduras) en donde Israel es una opción de salida. La emigración a Israel ha sido gradualmente el factor principal en las migraciones internacionales de la población judía latinoamericana, particularmente del cono sur. Más de 68.000 inmigrantes latinoamericanos llegaron a Israel entre 1948 y fines de 1983 (cerca de 40.000 de Argentina, 8.400 de Brasil, 7.800 de Uruguay, 5.000 de Chile, 2.600 de México y 4.300 de otros países). La intensidad general de la "aliá" (vocablo utilizado en el idioma hebreo para referirse a la emigración a Israel que significa "subida") desde los distintos países y el ritmo anual de variación de la tasa de la misma ha sido afectado fuertemente por los rápidos cambios en las condiciones socio-económicas y políticas de los diversos países latinoamericanos. Es importante recalcar que el fenómeno contrario, la reemigración de Israel, exhibe tasas relativamente bajas: 75-80\% de aquellos que llegaron desde 1969/70 se quedaron en el país después de los cruciales primeros tres años ${ }^{63}$ - En nuestros días se suman la inseguridad (plaga bastante común en Latinoamérica, básicamente Colombia y México, en lo referente a robos y secuestros) y las constantes crisis socioeconómicas (particularmente Argentina) e incertidumbre política (el caso de la Venezuela de Chávez) que están afectando a toda esta región, y que son claros indicadores de que la emigración continuará ${ }^{64}$.

\footnotetext{
${ }^{62}$ Levinc 1987:78.

${ }^{63}$ Schmelz y Delia Pergola.

${ }^{64}$ De quienes abandonan Latinoamérica obviamente no siempre su opción es Israel. Muchos optan principalmente por los Estados Unidos y Canadá.
} 
En cuanto al identificador Shoá, como elemento de identidad judía, ha adquirido cada vez más visibilidad, en el mundo entero, así como en América Latina. Después del pesado silencio que rodeó a este evento finalizada la segunda Guerra Mundial, gradualmente se reinició a considerar y atender lo que había ocurrido. Los sobrevivientes de la tragedia que llegaron a Latinoamérica terminada la guerra son considerados, se les brinda ayuda de todo tipo, y en algunos casos, se escriben sus memorias. Muchas comunidades de la región cuentan con museos que intentan mostrar lo ocurrido durante el Holocausto. Todas las escuelas judías cuentan con programas de remembranza de la Shoá. Las comunidades judías de Latinoamérica también participan en el programa de "La Marcha de la Vida", programa explicado en la sección de Holocausto como identificador. En la actualidad, este programa se extendió a varias escuelas judías, grupos de movimientos juveniles y grupos de adultos de la diáspora latinoamericana. Asimismo, en el campo académico el tema del Holocausto se ha incrementado. Ya son varias las universidades latinoamericanas en donde los cursos y las investigaciones acerca de este tema se llevan a cabo.

De variadas maneras y condiciones los cinco identificadores están representados por el judaísmo latinoamericano. Claro que después de un siglo de habitar estas tierras se da cierta "domesticación" de los elementos identitarios judíos que ya se localizan y adaptan a la realidad de estos países. El grupo judío en esta región ha logrado constituir y desarrollar vibrantes instituciones comunitarias y marcos identitarios propios; sin embargo en la actualidad son varias las dificultades que deben de ser consideradas. La asimilación expresada a través de los matrimonios mixtos y el alejamiento del judaísmo-, además del deterioro económico $^{65}$, la emigración y el debilitamiento de la identidad judía, son los problemas que enfrenta el judaísmo latinoamericano en la actualidad.

\footnotetext{
${ }^{65}$ La pauperización económica ha provocado marginalización comunitaria. Esto se manifiesta cesando de participar en diferentes instituciones judías (escuelas, sinagogas, actividades sociales y culturales) debido a no tener los medios económicos para continuar envueltos en tales actividades comunitarias.
} 


\section{CONCLUSIONES}

Se han señalado los cinco identificadores judíos considerados esenciales a principios del siglo XXI y sus expresiones y testimonios más generales dentro del judaísmo latinoamericano.

Tanto en Israel como en cualquier comunidad de la diáspora, todos los judíos reconocen y concuerdan que son estos los rasgos que caracterizan a la identidad judía en su totalidad, independientemente de su posición o grado de identificación frente a los mismos; sin importar la diferenciación en la evaluación privada o personal de cada judío frente a estos indicadores. Existe un consenso cultural entre los integrantes del grupo judío en tomo a estos rasgos a pesar y por encima del pluralismo interno.

Esta heterogeneidad debe ser vista a la luz de la posibilidad de un enriquecimiento espiritual y cultural interno. Es a partir del pluralismo, pero también paradójicamente pese al mismo, que la herencia cultural e identitaria del grupo judío se ha transmitido durante siglos. Son los rasgos comunes a todos sus integrantes lo que ha permitido su mantenimiento como pueblo.

Así como la Modernidad introdujo en el grupo judío las características comunes a este periodo, la era de la globalización hace su parte. Una sociedad más abierta, tanto en términos culturales como tecnológicos, nuevos factores de asociación y reproducción, van penetrando al interior del colectivo judío lo cual provoca, una vez más, que se articulen nuevas formas de vivir y experimentar el judaísmo en la época actual.

En términos generales, las fronteras grupales son cada vez más porosas, y el judaísmo latinoamericano no es ajeno a esta fragilidad en lo que se refiere a los límites identitarios judíos. La uniformidad que acompaña a la globalización es un fenómeno que está insertándose en el grupo judío y esto trae consigo la declinación de las diferencias, causando 
que los identificadores ya no sean fuente de distinción.

La identidad y la lealtad están expresadas en una multitud de formas. Al hablar del concepto de múltiples identidades, la idea básica es la no exclusión de identidades: se puede ser judío sin por eso renegar de la nacionalidad específica a la que se pertenece. Ninguna excluye a la otra. Hoy en día, dentro de la esfera de la globalización, con el pluralismo como su máxima expresión en el ámbito identitario, la aceptación de la doble identidad refleja un alto grado de conformidad del hecho de ser judío y también ciudadano del país donde habita. Quien se siente orgulloso de su judaísmo y a su vez se siente integrado a la sociedad que lo circunda, es aquel que experimenta la antítesis de la disonancia: ya que no ve ningún conflicto real entre ser judío y pertenecer a una nación.

\section{BIBLIOGRAFÍA}

AVINERI, SH. La idea Sionista. La Semana, Jerusalem, 1993.

AVNl, H. Judios en América. Cinco siglos de historia. España, Mapfre, 1992.

AVNI, H.

Presentación de las comunidades judías de América Latina. En Encuentro y Alteridad. Vida y cultura judía en América Latina. México, Universidad Nacional Autónoma de México, Universidad Hebrea de Jerusalén, Asociación Mexicana de Amigos de la Universidad de TelAviv y Fondo de Cultura Económica, 1999, pp. 15-31.

\section{BAER, A.}

"De memoria judía a memoria universal. El Holocausto y la globalización del recuerdo" Revista Anthropos (203):76-94, 2004.

\section{BÁRCENA,F.}

"Enseñar Auschwitz. El aprendizaje de una decepción". Revista Anthropos (203): 139-160, 2004.

BARON,S. W. La época moderna. Buenos Aires, Paidós, 1995. 
BARTH, F. Los grupos étnicos y sus fronteras. 1a ed. español, México, Fondo de Cultura Económica, 1976.

BAUER, Y. "A raíz de la discusión sobre el sionismo". Kivunim. Revista de Sionismo y Judaísmo. (octubre): 85-93, 1997.

BOKSER Liwerant, J.."The Impact of the Six-Day War on the Mexican Jewish Community" En The Six-Day War and the World Jewry. University Press of Maryland, USA. 2000, pp. 187-203.

BONFIL Batalla, G. Pensar Nuestra Cultura. México, Alianza, 1991.

BUCKSER, A. "Jewish Identity and the meaning of cornmunity in Denmark". En Ethnic and Racial Studies, pp. 23:4, 712-734, 2000.

CARO, 1. "Ortodoxias, disidencias y nuevas identidades en el judaísmo argentino y chileno" 2008, Proyecto FONDECYT, Chile (en prensa).

DELLA PERGOLA, S. "The Role of Community on Socio-Demographic Trends". En The Role 01 the Community Center in an Era 01 Uncertainty and Rapid Change Conference Report of the conference in Jerusalem, 7-9 December, 1998a.

DELLA PERGOLA, S. "Asimilación/Continuidad judía: tres enfoques". En Encuentro y Alteridad. Vida y cultura judía en América Latina. México, Universidad Nacional Autónoma de México, Universidad Hebrea de Jerusalén, Asociación Mexicana de Amigos de la Universidad de Tel-Aviv y Fondo de Cultura Económica, 1999, pp. 467-485.

DELLA PERGOLA, S.

"Jewish Identity/Assimilation/Continuity: Approaches to a Changing reality". En B. Waldman (Ed.) Cadernos de lengua e Literatur Hebraica 3. Faculdade de Filosofia, Letras e Ciéncias Humanas, Universidade de Sao Pablo, 2001a

EISEN, A. Rethinking Modern Judaism. Chicago \& London The University of Chicago Press, 1998.

ELAZAR, D. 1. "Reexaming the issue of Religion in the Public Square". En Jewish Political Studies Review, (1):1-2, 1999. 
ENCYCLOPAEDIA JUDAICA. Jerusalén, Keter Publishing House, 1999.

GARDELS, N. "Two Concepts of Nationalism: An Interview with Isaiah Berlin". New York Review 01 Books, 1991.

GIMÉNEZ,G. "Comunidades primordiales y modernización". En Modernización e identidades sociales. México, Universidad Nacional Autónoma de México, 1994, pp. 149-183.

GIMÉNEZ, G. "Materiales para una teoría de las identidades sociales". Frontera Norte 9( 18) :9-28, julio diciembre 1997.

GITELMAN, Z. "The decline of the Diaspora Jewish nation: Boundaries, Content, and Jewish Identity" Jewish Social Studies, 4:2, 112-132, winter 1998.

HAMUI Sutton, A. "Transformación en la religiosidad de los judíos en México tradición, ortodoxia y fundamenta-lismo en la Modernidad tardía". Tesis doctoral, Universidad Iberoamericana, México, 2003.

HERMAN, S. N. Jewish ldentity: a social psychological perspective. Sage Publications, Inglaterra, 1977.

KATZ, J. Out 01 the Guetto. Syracuse University Press, 1998.

LEVINE, R. M. "Adaptive Strategies of Jews in Latin America". En The Jewish Presence in Latin America. Boston, London Sidney, Allen \& Unwin: Wellington. 1987, pp. 71-84.

LEVY, D. C. "Jewish Education in Latin America". En The Jewish Presence in Latin America Boston, Allen \& Unwin, London Sydeny Wellington, 1987, pp. 157-184.

LINZER, N. "The Changing Nature of Jewish Identity". Journal of Jewish Communal Services, 72:3,142-150, 1996.

MINTZ, A. Popular Culture and the Shaping 01 Holocaust Memory in America. University of Washington Press, 2001.

Paths of emancipation: Jews, states, and citizenship Princeton, J, Princeton University Press, 1995, pp. 3-36

PÉREZ Ruiz, M. L. "La identidad como objeto de estudio". En 1 Seminario sobre identidad. Instituto de Investigaciones Antropológicas, Universidad Nacional Autónoma de México, 1992. 
PREMDAS, R. R. "Publíc policy and etbníc conflíct" Management of Social Translormation-MOST Discussion Paper Series - No. 12 http://www.unesco.org/most/premdas.htm\#author. 1997

ROZITCHNER, L. "Los judíos después de la Shoá" En La Identidad Judía [selección de artículos publicado en Le Monde Diplomatique], Santiago Chile, Editorial Aún Creemos en los Sueños, 2002.

SACKS, J. "From Integration to Survival to Continuity: The Great Era of Modern Jewry". En: Jewish ldentities in the New Europe. London, Littman Library of Jewish Civilization, 1994, pp. 107-116.

SÁNCHEZ-BIOSCA, V. "Equívocas sombras. La obstinada actualidad de Auschwitz". Revista Anthropos (203): $110-124,2004$.

SCHMELZ, U. O. Y DELLA PERGOLA, S. "La Demografía de los Judíos de Latinoamérica" Rumbos, 0:17-38 y $155-194,1985$.

SHAPIRO, E. S. "American Jews and the problem of identity" Society, ():14-19, September-october 1997.

SHLAIM, A. The lron Wall. lsrael and the Arab World. New, York, Norton \& Company, 2001.

VILLORO, L. Estado Plural, pluralidad de culturas. México, Paidós, 1998, pp: 63-78.

WEBBER, J. "Modern Jewish Identities: The Ethnographic Complexities". Joumal of Jewish Studies ( ):43:2, pp. 246-267, 1992. 